\title{
EDUCAÇÃO AMBIENTAL NA VISÃO DE PROFESSORES: CAMINHOS E REFLEXÕES
}

André Slaviero ${ }^{1}$

Bruno Fernandes Antunez ${ }^{2}$

Vidica Bianchi ${ }^{3}$

Maria Cristina Pansera-de-Araújo ${ }^{4}$

Resumo: $O$ presente artigo é resultado de uma pesquisa cujo foco foi a investigação das concepções de professores sobre Educação Ambiental (EA), com a realização de um estudo com 79 participantes. $\mathrm{Na}$ análise dos dados utilizou-se a Análise Textual Discursiva (ATD). Os resultados revelam que 1/4 dos professores possuem discursos mais conservadores em relação à EA e que, em contrapartida, $25 \%$ deles revelaram posicionamentos críticos sobre a EA. Dessa maneira, buscou-se refletir sobre o fomento de novos debates, sobretudo na formação inicial e continuada de professores sobre a temática.

Palavras-chave: Educadores; Concepções; Visão Crítica de EA; Visão Conservadora de EA.

Abstract: This article is the result of a research whose focus was the investigation of teachers' conceptions about Environmental Education (EE), with a study with 79 participants. In the data analysis, the Textual Discursive Analysis (ATD) was used. The results reveal that $1 / 4$ of the teachers have more conservative discourses in relation to $\mathrm{EE}$ and that, on the other hand, $25 \%$ of them revealed critical positions about EE. Thus, we sought to reflect on the encouragement of new debates, especially in the initial and continuing education of teachers on the subject.

Keywords: Educators; Conceptions; Critical View of EE; Conservative View of EE.

\footnotetext{
${ }^{1}$ Universidade Federal do Rio Grande do Sul (UFRGS). E-mail: andre.slaviero@ufrgs.br. Link para o Lattes: http://lattes.cnpq.br/8201082159049324

2 Universidade Federal do Tocantins (UFT). E-mail: brunoantunez@uft.edu.br.

Link para o Lattes: http://lattes.cnpq.br/3490139239498750

${ }^{3}$ Universidade Regional do Noroeste do Estado do Rio Grande do Sul (UNIJUÍ). E-mail: vidica.bianchi@unijui.edu.br. Link para o Lattes: http://lattes.cnpq.br/3979701002447139

${ }^{4}$ Universidade Regional do Noroeste do Estado do Rio Grande do Sul (UNIJUÍ). E-mail: pansera@unijui.edu.br. Link para o Lattes: http://lattes.cnpq.br/6707424118316750
} 


\section{Introdução}

A humanidade enfrenta inúmeros problemas de caráter socioambiental, que se caracterizam como ameaças aos ecossistemas e à manutenção da saúde, bem-estar e vida dos seres vivos. Tornam-se comuns, desse modo, alertas vindos de pesquisadores e ambientalistas para a população em geral, no intuito de esclarecer a respeito das mudanças que ocorrem e que muitas vezes são irreversíveis, em que o Planeta Terra é alvo da ação humana e da irresponsabilidade socioambiental. A forma predatória como as sociedades apoderaram-se (e continuam com esta usurpação) dos bens e recursos naturais, bem como 0 aumento populacional e o crescimento urbano desordenado (ARANTES; UEHARA, 2021) agravaram fortemente a degradação ambiental e expandiram avassaladoramente os patamares dos prejuízos causados à qualidade e preservação da vida (MARQUES FILHO, 2018).

O uso da natureza pelos seres humanos a seu bel prazer, principalmente quando apropriada por grandes indústrias, movidas por ideais puramente econômicos, tem por trás o modelo de produção capitalista (LOUREIRO; LAYRARGUES, 2013). Nesse viés, o campo educacional e o ensino, principalmente 0 básico e público, em que enormes parcelas de crianças, jovens e adolescentes de diferentes realidades constituem um espaço para questionar os enfrentamentos sociais das mais diversas ordens. Esta situação torna fundamental a inserção de debates e temáticas socioambientais, a fim de contestar tais problemas com discernimento e entendimento crítico da situação, numa perspectiva sistêmica, capaz de vincular a permanência dos recursos e o respeito ao ambiente.

Não obstante, esse público enfrenta em sua realidade diferentes mazelas, que muitas vezes se constituem como obstáculos ao processo educativo, a exemplo da fome, da pobreza, da falta de saneamento básico, da vulnerabilidade, do racismo, da violência, de moradias precárias e da carência de recursos financeiros e diversas outras questões, que acabam por asseverar as desigualdades, como que num retrato da época atual.

Ciente dos desafios e na busca da articulação entre os campos socioambiental e educativo, a Educação Ambiental (EA) é uma prática que reconhece na educação um alicerce para instituir mudanças nas formas de pensar e agir perante a relação homem-natureza. É entendida como uma educação política comprometida com o social, que amplia a cidadania, a autonomia e a liberdade de intervir para/pelo e movida pelo bem comum (REIGOTA, 2017).

Possui "[...] o compromisso político de questionar o modo como estão postas as relações entre humanidade e a natureza, entre o modelo de produção e as desigualdades sociais" (OLIVEIRA, 2018, p. 5). Leff (2015, p. 250) complementa: 
A Educação Ambiental tenta articular subjetivamente 0 educando à produção de conhecimentos e vinculá-lo aos sentidos do saber. Isto implica fomentar o pensamento crítico, reflexivo e propositivo face às condutas automatizadas, próprias do pragmatismo e do utilitarismo da sociedade atual.

$\mathrm{Na}$ legislação brasileira, à luz da Política Nacional de Educação Ambiental - PNEA, Lei no 9.795/1999 (BRASIL, 1999) - e das Diretrizes Curriculares Nacionais para a Educação Ambiental - DCNEA, Resolução no 2,de 15 de junho de 2012 (BRASIL, 2012) - ambas do Ministério da Educação (MEC) e do Conselho Nacional de Educação (CNE), existem os preceitos de que a EA é componente essencial e permanente da educação nacional, comprometida com a construção contínua de uma sociedade justa e promotora de sustentabilidade (BRASIL, 1999, 2012).

De fato, os documentos apontam preocupação com o desenvolvimento de uma EA de forma transdisciplinar, enquanto processo coletivo voltado à compreensão integrada do meio ambiente em suas relações e aspectos, incumbindo ao poder público a promoção de tais políticas baseadas em linhas de condução (BRASIL, 1999). É questionado, todavia, se realmente ocorre este tipo de prática no ensino formal e não formal, bem como se os educadores possuem formação (inicial ou continuada) para trabalharem essa temática e garantirem sua imersão nos currículos, não como disciplina, mas, sim, de forma integrada e contínua nos diferentes níveis e modalidades de ensino.

Neste sentido, esta investigação pretende analisar e discutir a percepção dos professores sobre a EA a partir das categorias que indicam Discurso Tradicional/Conservador de EA ou Discurso Transformador/Crítico ou Emancipatório (LIMA, 2002; LOUREIRO, 2005; SAUVÉ, 2005; SOUZA, 2016). Como hipótese, tem-se que os professores, em sua maioria, apresentam percepções tradicionais sobre a EA, corroborando para manter o cenário enfrentado hoje em dia, cujos reflexos na educação se restringem a abordagens, práticas e preocupações com interesse em conservar e/ou preservar o meio ambiente, sem questionar as raízes dos problemas emergentes e urgentes do contexto atual, principalmente os de ordem socioambiental.

Dessa forma, a presente análise objetiva explorar as concepções de EA de professores e profissionais liberais de diferentes instituições educativas do Brasil.

\section{Encaminhamentos metodológicos}

O estudo se caracteriza como observacional transversal de caráter descritivo (THOMAS; NELSON; SILVERMAN, 2012). Compõe uma das atividades da disciplina de Educação Ambiental em Instituições Educativas do currículo do Programa de Pós-Graduação Stricto Sensu em Educação nas 
Ciências da Universidade Regional do Noroeste do Estado do Rio Grande do Sul (PPGEC - Unijuí).

A pesquisa proposta consistiu de um questionário semiestruturado no Google Forms, elaborado pelas docentes da disciplina, com a intenção de conhecer as percepções de professores de diferentes instituições educativas do território nacional sobre EA, ações de EA, sustentabilidade ambiental e Objetivos do Desenvolvimento Sustentável.

O critério de seleção da amostra foi do tipo intencional não probabilístico, em que cada estudante matriculado na disciplina respondeu ao questionário e o enviou para mais 3 pessoas (professores da educação básica ou superior ou para profissionais liberais), totalizando 79 sujeitos respondentes. Para tanto, com as respostas (corpus de análise) utilizou-se a Análise Textual Discursiva (ATD) (MORAES; GALIAZZI, 2016), para facilitar a compreensão dos resultados, a elaboração das categorias mediante formulação das hipóteses e a construção de argumentos. No mês de maio de 2021, os dados foram coletados e registrados em planilha on-line, a partir da plataforma "Google Formulários" com perguntas abertas e fechadas.

O instrumento para coleta continha 18 questões: 6 para delinear o perfil profissional dos sujeitos e as outras 12 questões sobre EA, a saber:

1 - Como você define a Educação Ambiental (EA)?

2 - Quais são as suas preocupações com as questões ambientais?

3 - A instituição em que atua faz EA na integração com a comunidade?

4 - Você se considera educador ambiental? Justifique.

5 - O que são os Objetivos de Desenvolvimento Sustentável (ODS)?

6 - Quais são as ações necessárias para alcançar os ODS na sua região?

7 - Você participa de cursos ou formação continuada relacionada à EA ou áreas afins? Quais?

8 - A instituição em que você trabalha possui alguma atividade ou projeto para preservação do Meio Ambiente (MA) ou de EA? Qual(is)? 9 - Você aborda os temas MA e EA na sua disciplina ou área de atuação? Explique.

10 - Em sua opinião, em quais disciplinas ou campos de atuação é possível trabalhar as questões ambientais?

11 - Cite os limites de trabalhar temas relacionados ao MA e EA com seus alunos.

12 - Cite as possibilidades de trabalhar temas relacionados ao MA e EA com seus alunos.

Como dito, na parte inicial do instrumento de coleta havia a caracterização dos participantes, incluindo as informações sobre gênero, faixa etária, curso de Graduação, campo de atuação (Educação Básica, Ensino Superior, Profissional Liberal ou outro), área em que atua e há quanto tempo desempenha suas funções. Todos os participantes tiveram sua identidade 
preservada e não houve qualquer mecanismo que possibilitasse a sua identificação. Ao longo do texto, conforme são citados os participantes da pesquisa, atribui-se a letra "R" (resposta) e subsequente número, por exemplo, R1, R2, R3, e assim sucessivamente.

As pessoas contatadas aceitaram participar da pesquisa quando responderam às perguntas. O projeto norteador da pesquisa (Desenvolvimento do pensamento crítico em acadêmicos do Ensino Superior sobre sustentabilidade ambiental e educação em saúde na perspectiva das relações entre ciência, tecnologia, sociedade e ambiente) foi submetido ao Comitê de Ética em Pesquisa, na Unijuí, e aprovado com o no 3.642.360.

Nesse texto, são analisadas as respostas da primeira questão, sistematizando-as em duas categorias, que emergiram das mesmas e que possibilitam diálogos com a literatura. A escolha dessa pergunta está assentada nos saberes mobilizados para a produção de tais respostas, por meio da avaliação das compreensões dos respondentes quanto às definições de EA.

A Análise Textual Discursiva (ATD) de Moraes e Galiazzi (2016) fundamentou o processo, pois

[...] se inicia com uma unitarização em que os textos são separados em unidades de significado. Estas unidades por si mesmas podem gerar outros conjuntos de unidades oriundas da interlocução empírica, da interlocução teórica e das interpretações feitas pelo pesquisador. Neste movimento de interpretação do significado atribuído pelo autor exercita-se a apropriação das palavras de outras vozes para compreender melhor o texto. Depois da realização desta unitarização, que precisa ser feita com intensidade e profundidade, passa-se a fazer a articulação de significados semelhantes em um processo denominado de categorização. Neste processo reúnem-se as unidades de significado semelhantes, podendo gerar vários níveis de categorias de análise. A análise textual discursiva tem no exercício da escrita seu fundamento enquanto ferramenta mediadora na produção de significados e por isso, em processos recursivos, a análise se desloca do empírico para a abstração teórica, que só pode ser alcançada se o pesquisador fizer um movimento intenso de interpretação e produção de argumentos. Este processo todo gera metatextos analíticos que irão compor os textos interpretativos (MORAES; GALIAZZI, 2016, p. 118).

Ademais, as respostas e as categorias associadas foram analisadas e discutidas a partir dos fundamentos teóricos expressos por Lima (2002), Loureiro (2005) e Sauvé (2005), cujas reflexões embasam o diálogo com pressupostos do campo da EA e afins. 


\section{Resultados e discussão}

"Análises qualitativas de materiais textuais implica assumir interpretações de enunciados dos discursos, a partir dos quais os textos são produzidos, tendo consciências de que isso sempre envolve a própria subjetividade" (MORAES; GALIAZZI, 2016, p. 135), que justificam a construção de unidades de significado, a partir dos elementos da pesquisa, sistematizando os dados em categorias, conforme a ATD dispõe (MORAES; GALIAZZI, 2006, 2016).

Foram analisadas as respostas de 79 professores (63 do sexo feminino e 16 do masculino). A maior parte (64,5\%) encontrava-se na faixa etária entre 26 e 45 anos de idade. Em relação ao campo de atuação, 78,5\% deles atua na rede básica de ensino, $12,7 \%$ na educação superior, $1,3 \%$ como profissional liberal e 7,6\% dos respondentes não especificaram. Quanto ao tempo de atuação na instituição, 49,4\% estavam exercendo sua profissão há mais de 10 anos; $12,7 \%$, de 7 a 9 anos; 22,8\%, de 4 a 6 anos; e 15,2\%, de 1 a 3 anos.

A Figura 1 apresenta a distribuição da amostra de acordo com o curso de formação superior:

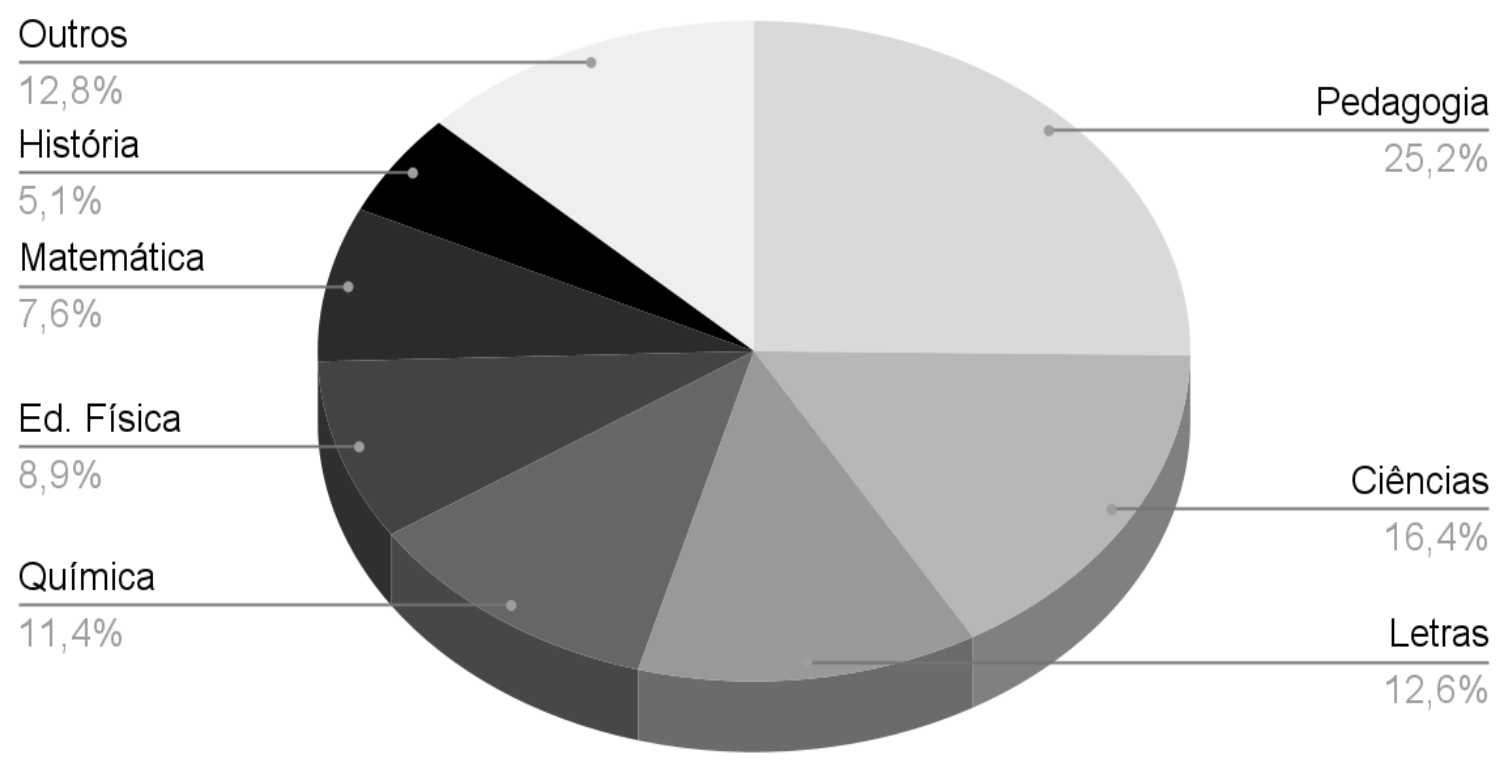

Figura 1: Distribuição percentual dos professores por curso de formação superior $(n=79)$.

Fonte: Dados da Pesquisa, 2021.

Percebe-se que o grupo de 79 pesquisados é constituído em sua maioria por pedagogos ( $1 / 4$ do corpus), seguido por professores de Ciências Biológicas, de Letras e de Química. Merece destaque a heterogeneidade do grupo, com 7 cursos de Graduação identificados nas respostas e "Outros", que somaram o percentual de $12,8 \%$, demonstrando a presença de diferentes 
formações iniciais dos participantes e a atuação destes em distintas áreas, por exemplo, na Educação Infantil, nos Anos Iniciais do Ensino Fundamental, nos Anos Finais do Ensino Fundamental e na Direção ou Supervisão Escolar, entre outras.

Dessa forma, a partir do detalhamento dos sujeitos investigados, percebe-se conformidade com as legislações nacionais sobre EA (PNEA e DCNEA), quando estas preconizam que a EA seja desenvolvida no âmbito dos currículos escolares de todos os níveis, etapas e modalidades (BRASIL, 1999, 2012), buscando alcançar estágios mais sustentáveis e com menos injustiças, desigualdades e apropriações insensatas da natureza.

Feita essa caracterização dos respondentes, partiu-se para a análise das respostas e do seu agrupamento, a partir dos significados que exprimem (categorização), conforme os preceitos da ATD (MORAES; GALIAZZI, 2006, 2016). Posto isso, optou-se por utilizar as categorias a priori e argumentos de Loureiro (2005) e Sauvé (2005), que propõem uma sistematização das formulações teóricas e correntes de EA, apresentando blocos e correntes de $E A$, respectivamente, e propondo correspondências entre os diferentes discursos concebidos e praticados, cada qual de sua forma, em relação à ação educativa neste campo.

Dadas as semelhanças entre o que fora elencado a partir da interpretação das respostas e o que consta nos materiais supracitados Loureiro (2005) e Sauvé (2005) - preferiu-se agrupar as respostas em Categoria 1 - Discurso Tradicional ou Conservador de EA - e Categoria 2 Discurso Transformador/Crítico ou Emancipatório.

Essa diferenciação do campo da EA é necessária ante o cenário vivenciado e em consideração à ampla variedade de posicionamentos e visões que demarcam seus espaços no cotidiano. Assim, as respostas dadas no questionário para a Questão 1 foram classificadas conforme as definições elaboradas para as duas Categorias, expressas a seguir:

Categoria 1 - Discurso Tradicional ou Conservador de EA: engloba todas as respostas que abordam ou trazem indícios de que a crise ambiental possui um viés naturalista ou conservador, com pouca problematização da realidade, dos modos e relações estabelecidas entre a produção e o consumo, cujos objetivos residem na mudança individual de comportamento, com ausência de reflexões (SOUZA, 2016). Além disso, as perspectivas educacionais nessa categoria assumem uma posição hegemônica dentro da EA.

Categoria 2 - Discurso Transformador/Crítico ou Emancipatório: abrange as respostas com concepções e/ou práticas que possibilitam uma análise da realidade social complexa e contraditória, como ação política, que busca autonomia e liberdade social, reconfigurando as relações homem-natureza e a participação social e cidadã, bem como a construção de valores (SOUZA, 2016). 
Os resultados indicam que, para a primeira questão do instrumento da pesquisa, cujo interesse era conhecer as definições de EA, grande parte dos que responderam ao questionário estão enquadrados na Categoria 1 do estudo, totalizando 59 respostas, correspondendo a $74,7 \%$ do total dos respondentes. As respostas dos demais 20 sujeitos (25,3\% do todo) foram alocadas na Categoria 2.

Esses resultados revelam que os caminhos de EA retratados nas respostas obtidas são e estão voltados a interesses mais conservadores, o que acaba por afetar e manter de forma direta os padrões atuais das sociedades e as relações mantidas com os ambientes que garantem o sustento das populações. Os excertos do Quadro 1 exemplificam algumas das respostas presentes na Categoria 1:

Quadro 1: Excertos das respostas relativas a EA, ilustrativos da Categoria 1 - Discurso Tradicional ou Conservador de EA.

Pergunta 1: Como você define a Educação Ambiental (EA)?

R7: O ensino de tudo aquilo que envolve questões voltadas para o meio ambiente.

R11: Uma área de suma importância para o desenvolvimento da consciência de conservação e preservação do ambiente.

R19: São ações através das quais os sujeitos constroem valores, conhecimentos, habilidades e competências voltadas à conservação do meio ambiente e sua sustentabilidade.

R33: Ensino e cuidado com o meio ambiente.

R49: Parte da Educação que tem como objeto de estudo os problemas ambientais.

R56: Educação Ambiental é o caminho pelo qual os indivíduos e a coletividade constroem valores, conhecimentos sobre como se deve preservar o meio ambiente, vez que este é essencial à sadia qualidade de vida.

R63: Formar cidadãos visando o desenvolvimento econômico aliado à preservação e conservação dos recursos naturais.

Fonte: Elaborado pelos autores.

Nota-se que as respostas carregam compreensões que, em alguns casos, são simplistas ou contraditórias do que seria a EA, relegando-a como "Parte da Educação" (R49) ou então voltada ao "desenvolvimento econômico" (R63). Ainda que a maioria dos respondentes sejam majoritariamente atuantes na Educação Básica ou no Ensino Superior, nota-se que associaram a palavra 
"Educação" de Educação Ambiental com o "Ensino" (R7 e R33), reduzindo a Educação Ambiental a essa única abordagem. Da mesma forma, as palavras "Conservação" (R11, R19 e R63) e "Preservação/preservar" (R11, R56 e R63) revelam aproximação com correntes conservacionistas/recursistas (SAUVÉ, 2005), na ideia de natureza-recurso que precisa ser mantida. Nesse cenário, são muito comuns os programas com foco nos famosos $3,5,7$ ou até mesmo 8 R's já conhecidos (Reciclar, Reduzir, Reutilizar, Refletir, Respeitar, Reparar/Recuperar, Responsabilizar-se e Repassar).

Embora algumas respostas retratem aspectos sobre a "Importância" (R11) da EA na construção de "Valores, conhecimentos, competências e habilidades" (R19), considerando o âmbito dos "Indivíduos e a coletividade" (R56), o que se sobressai, ainda, é a essência unilateral da questão ambiental, numa abordagem despolitizada, e a ausência de perspectiva crítica, conforme ressalta Lima (2002).

O mesmo autor salienta que

[...] um entendimento reducionista da crise ambiental não favorece a tomada de iniciativas em defesa da qualidade de vida, a responsabilização dos verdadeiros agentes da degradação e a luta por direitos ambientais enquanto direitos de cidadania. Por outro lado, politizar o debate e a educação ambientais pode significar, justamente, um estímulo à compreensão dos riscos presentes nas agressões ambientais, à identificação e responsabilização dos reais agentes da degradação, ao reconhecimento do acesso a um ambiente limpo como uma conquista cidadã e à participação organizada na resolução dos problemas comunitários. A conjunção desses processos pode abrir caminhos profícuos para a construção de uma sustentabilidade emancipatória apoiada na defesa da vida em largo sentido, da liberdade e da justiça social (LIMA, 2002, p. 13).

Essa perspectiva de mudança social embasa as compreensões da Categoria 2, ligada ao viés emancipatório da EA, com $25,3 \%$ de respondentes. Mais alarmante que isso é perceber que, dentro da compreensão transformadora da EA, lócus para o estabelecimento de ações políticas capazes de questionar paradigmas e de olhar criticamente as relações sociais e ambientais, uma quantidade três vezes menor de professores, comparando com os da primeira categoria, indicou pertencer a este grupo.

Em contrapartida, as respostas incluídas na Categoria 2 revelam posicionamentos críticos ante os desafios da crise socioambiental (Quadro 2), de modo que esses docentes refletem ou indicaram nas respostas uma perspectiva reflexiva sobre suas ações no coletivo, e desenvolvem ou buscam desenvolver um movimento de desalienação, disruptura e superação de problemas socioambientalmente estruturados. 
Quadro 2: Excertos das respostas relativas a EA, ilustrativos da Categoria 2 - Discurso Transformador/Crítico ou Emancipatório.

Pergunta 1: Como você define a Educação Ambiental (EA)?

R9: Um campo da educação que trabalha com a relações entre o ser humano e o ambiente do qual faz parte (em nível individual, coletivo e sistêmico) a partir de uma perspectiva crítica.

R50: É uma possibilidade de encontrar-nos com o ambiente, reconhecer que o homem faz parte desse equilíbrio e que suas ações são parte das dinâmicas ambientais. Então a Educação Ambiental é um campo de conhecimento ligado ao desenvolvimento dos cidadãos.

R65: Considero que a Educação Ambiental é um processo formativo que visa abordar conceitos ambientais e, principalmente, favorecer a tomada de consciência sobre como as questões ambientais estão inter-relacionadas com aspectos econômicos, políticos e sociais.

R77: Penso que a Educação Ambiental é a ação educativa permanente pela qual a comunidade educativa tem a tomada de consciência de sua realidade global, do tipo de relações que os homens estabelecem entre si e com a natureza, dos problemas derivados de ditas relações e suas causas profundas, ou seja, seria um processo permanente no qual os indivíduos e a comunidade tomam consciência do seu meio ambiente e adquirem conhecimentos, habilidades, experiências, valores e a determinação que os tornam capazes de agir individualmente ou coletivamente na busca de soluções para os problemas ambientais presentes e futuros.

Fonte: Elaborado pelos autores.

Trata-se de vincular o desenvolvimento de cidadania ativa com a articulação de possibilidades que contemplem propostas mais justas e igualitárias de conceber um equilíbrio entre a vida humana no planeta. No que concerne ao "educar", ressalta-se a importância de uma pedagogia da autonomia, que se volte ao letramento científico e que garanta aprendizagens significativas no contexto estudantil. Como bem expõe Loureiro (2005, p. 1.484, grifo do autor):

A ação emancipatória é o meio reflexivo, crítico e autocrítico contínuo pelo qual podemos romper com a barbárie do padrão vigente de sociedade e de civilização, em um processo que parte do contexto societário em que nos movimentamos, do "lugar" ocupado por cada sujeito [...].

Além disso, as categorias definidas no estudo, em consonância com o que outros pesquisadores já apontaram (LIMA, 2002; LOUREIRO, 2005; SAUVÉ, 2005; SOUZA, 2016), reforçam a importante distinção que deve haver 
quando se pensa, planeja, projeta ou anseia-se trabalhar e desenvolver ações neste campo da educação. Afinal, conforme Lima aponta,

Para o observador desatento parece que falam todas a mesma linguagem e compartilham os mesmos valores, objetivos, interesses e ideologias. $\mathrm{Na}$ verdade, ao observar-se atentamente o diverso e múltiplo campo da EA podemos perceber que as aparências escondem diferenças sutis e essenciais com relação aos meios e, sobretudo, às finalidades da EA. Essa constatação, portanto, justifica a necessidade crescente de se diferenciar internamente o campo da EA identificando e discernindo os conteúdos que informam suas principais tendências e permitindo, desta forma, visualizar os futuros prováveis que cada uma dessas tendências aponta (2002, p. 7).

Ainda, "Cabe destacar que não estamos afirmando que somente existam esses dois blocos, pois poderíamos lembrar de experiências e pensadores que não se enquadram estritamente e que apresentam proximidades ou não com eles de acordo com suas orientações específicas" (LOUREIRO, 2005, p. 1.475), mas em relação às respostas, "Essa sistematização [...] torna-se uma ferramenta de análise a serviço da exploração da diversidade de proposições pedagógicas e não um grilhão que obriga a classificar tudo em categorias rígidas, com o risco de deformar a realidade" (SAUVÉ, 2005, p. 17-18). Em suma, acredita-se que explicitar o que os professores pesquisados responderam é um caminho para (re)pensar e (re)examinar as práticas docentes no que diz respeito, principalmente, às abordagens e compreensões e às maneiras de desenvolver formas para que a questão socioambiental faça parte do ensino.

\section{Considerações finais}

O que se verificou, de fato, foi que a maioria dos respondentes indicou fazer parte ou assumir um posicionamento tradicional no campo da EA, fundamentando-se, principalmente, em valores de preservação e conservação da natureza, sem questionar o porquê de suas ações ou sobre como as relações entre a sociedade do consumo e a forte exploração de bens naturais interferem no equilíbrio ecológico do planeta e na manutenção das condições essenciais para a vida do/no planeta.

O ser humano vem agravando e acelerando as crises socioambientais, cuja base é resultado das sociedades industriais exacerbando os excedentes, com o olhar único para a economia, e menosprezando os limites ecológicos e éticos. Diante desse cenário deflagrado por inúmeros órgãos mundiais, é fundamental haver ação, voltada para a reversão do cenário e que possibilite o repensar, não apenas do que é feito no campo da $E A$, mas também almejar 
posicionamentos críticos ante as formas que as circunstâncias atuais tomaram e com atenção permanente quanto ao futuro.

Buscou-se refletir sobre o que os professores, em sua maioria, concebem sobre EA, com o emprego de suas intencionalidades, no desenvolvimento de práticas nos ambientes acadêmicos e/ou escolares. Essa publicação espera fomentar novos debates, associando conhecimentos e valores em sintonia com a dimensão da transformação social, quer sejam eles nos espaços de formação da Educação Básica e do Ensino Superior, ou nas formações iniciais e continuadas de professores.

Em síntese, sabendo-se dos campos plurais e diversos da EA, da mesma maneira que a natureza não espera e os recursos naturais são finitos, é fato que a EA, portanto, constitui uma potencial ferramenta para revolucionar ou modificar as concepções capitalistas ainda preponderantes na atualidade, visto que outras concepções de Educação(ões) Ambiental(is) comprometidas com as temáticas socioambientais são cruciais nos processos formativos.

\section{Referências}

ARANTES, H. O.; UEHARA, S. C. S. A. Conhecimento e prática de professores do ensino básico em Educação Ambiental e saúde. Revista Brasileira de Educação Ambiental, v. 16, n. 4, p. 169-190, 2021.

BRASIL. Lei no 9.795, de 27 de abril de 1999. Institui a Política Nacional de Educação Ambiental. Diário Oficial da União, seção 1. Brasília/DF, 28 abr. 1999.

BRASIL. Resolução no 2, de 15 de junho de 2012. Estabelece as Diretrizes Curriculares Nacionais para a Educação Ambiental. Brasília, DF: Presidência da República, 2012.

LEFF, E. Saber ambiental: sustentabilidade, racionalidade, complexidade, poder. Tradução Lúcia Mathilde Endlich Orth. 11. ed. Petrópolis/RJ: Vozes, 2015.

LIMA, G. F. C. Crise ambiental, educação e cidadania: os desafios da sustentabilidade emancipatória. In: LAYRARGUES, P. P.; CASTRO, R. S.; LOUREIRO, C. F. B. (Orgs.). Educação Ambiental: repensando o espaço da cidadania. São Paulo: Cortez, 2002.

LOUREIRO, C. F. B. Complexidade e dialética: contribuições à práxis política e emancipatória em Educação Ambiental. Educação \& Sociedade, Campinas/SP: CEDES, v. 26, n. 93, p. 1.473-1.494, set./dez. 2005.

LOUREIRO, C. F. B.; LAYRARGUES, P. P. Ecologia política, justiça e Educação Ambiental crítica: perspectivas de aliança contra-hegemônica. Trabalho, Educação e Saúde, Rio de Janeiro, v. 11, n. 1, p. 53-71, jan./abr. 2013. 
MARQUES FILHO, L. C. Capitalismo e colapso ambiental. 3. ed. revista. Campinas/SP: Editora da Unicamp, 2018.

MORAES, R.; GALLIAZI, M. C. Análise textual discursiva: processo reconstrutivo de múltiplas faces. Ciência \& Educação, Bauru/SP, v. 12, n. 1, p. 117-128, 2006.

MORAES, R.; GALLIAZI, M. C. Análise textual discursiva. 3. ed. ljuí: Editora Unijuí, 2016.

OLIVEIRA, T. N. A dimensão política da Educação Ambiental: experiências significativas do professor na educação básica. 2018. Dissertação (Mestrado em Educação) - Instituto de Biociências, Universidade Estadual Paulista Júlio de Mesquita Filho, Rio Claro/SP, 2018.

REIGOTA, M. O que é Educação Ambiental. São Paulo: Brasiliense, 2017.

SAUVÉ, L. Uma cartografia das correntes em Educação Ambiental. Tradução Ernani Rosa. In: SATO, M.; CARVALHO, I. C. M. (orgs.). Educação Ambiental: pesquisa e desafios. Porto Alegre: Artmed, 2005. p. 17-44. Cap. 1.

SOUZA, V. M. de. Para o mercado ou para a cidadania? A Educação Ambiental nas instituições públicas de ensino superior no Brasil. Revista Brasileira de Educação, v. 21, n. 64, p. 121-140, jan.-mar. 2016.

THOMAS, J.; NELSON, J.; SILVERMAN, S. Métodos de pesquisa em atividade física. 6. ed. Porto Alegre, RS: Artmed, 2012. 